\title{
Destination governance in times of change: a complex adaptive systems perspective to improve tourism destination development
}

\author{
Stefan Hartman
}

\begin{abstract}
Purpose - This paper brings together the literature on theories of complexity adaptive systems (CAS), develops an analytical framework, applies this framework to the development of tourism destinations and critically reflects on the use of this perspective.

Design/methodology/approach - This paper elaborates on a CAS perspective on destination development, to further develop complexity thinking in tourism studies. This approach enables to identify policy avenues geared towards improving destination governance and contributing to sustainable tourism development.

Findings - Theories of CAS offer an analytical lens to better understand destination development, drawing explicit attention to (1) the levels of the individual, (emergent) structures, the structure-agency interface and the system level, (2) the steps related to the process of adaptation that is critical for systems to survive and thrive in times of change and (3) the undervalued importance of considering the factor of time.

Originality/value - Applying CAS theories help to address a range of (policy) avenues to improve destination governance, contributing to a shift in focus from reactively fixing problems to proactively addressing the structural issue of adaptive capacity building. It shows that managing tourism destination as complex systems involves a set of conditions that are critical as well as difficult to meet in tourism practice.
\end{abstract}

Keywords Governance, Resilience, Complexity, Destination development, Adaptive capacity

Paper type Research paper

\section{Introduction}

Tourist destinations are in a constant state of change, to a greater of lesser extent. It is the result of the ongoing interplay between autonomous, external pressures such as economic fluctuations, geopolitics, climate change, natural disasters, epidemics (COVID-19), changes in demography, visitor behavior and many more that trigger responses by actors that affect how destinations develop and evolve over time. As a result of ongoing actions of actors and their outcomes, tourism destinations can be conceptualized as being in persistent state of becoming (cf. Boelens and De Roo, 2016). Over longer periods of time, the structures, functions, identities, cultures and practices of these spaces and places may even change fundamentally/nonlinearly (Hartman et al., 2019).

There is an emerging school of thought in the tourism literature that explores theories of complexity and complex adaptive systems aiming to further conceptualize this dynamic-adaptive behavior of destinations, framing destinations as complex (adaptive) systems (Faulkner and Russel, 1997; Farrell and Twining-Ward, 2003; Baggio, 2008; Schianetz and Kavanagh, 2008; Stevenson et al., 2009, Baggio et al., 2010; Brouder and Eriksson, 2013; Ma and Hassink, 2013; Hartman, 2016; Yang et al., 2019). These contributions aim to create a better understanding of the complexities of destination development and how to manage such complexity. Theorizing tourism destinations as complex adaptive systems allows for projecting perspectives on destinations concerning
Stefan Hartman is based at the European Tourism Futures Institute (ETFI), NHL Stenden University of Applied Sciences, Leeuwarden, The Netherlands and Cultural Geography, Faculty of Spatial Sciences, University of Groningen, Groningen, The Netherlands.

Received 26 November 2020 Revised 16 February 2021 Accepted 20 April 2021

(C) Stefan Hartman. Published in Journal of Tourism Futures.

Published by Emerald Publishing Limited. This article is published under the Creative Commons Attribution (CC BY 4.0) licence. Anyone may reproduce, distribute, translate and create derivative works of this article (for both commercial and noncommercial purposes), subject

to full attribution to the original publication and authors. The full terms of this licence may be seen at http://creativecommons.org/ licences/by/4.0/legalcode

This paper is part of the research project Building Adaptive Tourism Areas, funded by the Taskforce for Applied Research (in Dutch: Nationaal Regieorgaan Praktijkgericht Onderzoek SIA), part of the Netherlands Organisation for Scientific Research (NWO). Grant no. HBOPD.2018.01.006. 
important characteristics and key conditions that enable destinations to perform such dynamicadaptive behavior that allows them to survive and thrive in dynamic contexts (Hartman, 2020). Such complex adaptive systems (CAS) perspectives can offer analytical leverage particularly to help understand system dynamics of destinations as well as the extent to which characteristics and requirements are in place that enable dynamic-adaptive behavior. A CAS perspective could then help to identify policy avenues to resolve tourism-related issues that emerge on societal, political and policy agendas. For instance, issues such as overtourism that reflect suboptimal destination governance can serve as feedback (or feedforward) mechanisms for improving destination governance - in line with understandings of "metagovernance" as the reflexive reframing of systems of governance in response to failure (Jessop, 2011; Amore and Hall, 2016).

This paper elaborates on a complex adaptive systems perspective and applies this perspective to tourism destination development, aiming to explore policy avenues to improve destination governance, so it aligns better to the dynamic nature of destination development in the context of today's network society and globalizing economy. Governance is used in this paper to refer to "associational networks of private (market), civil society (usually NGO) and state actors" and how they engage "in rule-making, rule-setting and rule implementation at a variety of geographical scales" (Swyngedouw, 2005, p. 1992). This paper contributes to the current body of knowledge by (1) providing a comprehensive overview of system dynamics and associated key aspects, (2) presenting a framework of concepts and mechanisms that offer analytical leverage to better understand tourism destination development, (3) identifying policy avenues that may help to improve destination governance and (4) reflecting on the use of CAS theories in a tourism context. To achieve the goals and aims of this paper, Section 2 provides a review of theories of complex adaptive systems and brings findings together in a framework of concepts and mechanisms. In Section 3, this framework of concepts and mechanisms is applied to destination development to identify policy avenues that may help to improve destination governance. A reflection is given in Section 4 on the use of this CAS perspective in a tourism context.

\section{Complexity theory perspective on system dynamics}

\subsection{Tourism destinations as complex systems}

Tourism destinations consist of interrelated actors, products, sectors and institutions (Ma and Hassink, 2013). They can be conceptualized as systems because elements, agents and their actions are tied very closely to other elements, agents and their actions (Axelrod and Cohen, 2000). Moreover, they are complex as within these systems a range of actors are continually engaged in decision-making, deploying initiatives, interactions, negotiations, cocreation, coalition building, collective action, and so on. The ways in which these in-system processes take place, play out, reinforce or frustrate each other will over time determine which structures (physical, organizational and institutional) emerge at a system level and can be observed as such (Allen, 2012). Also, complex adaptive systems are considered to be "open systems" as interactions and actions of actors within these systems are influenced by factors that stem from their outside contextual (or external) environment (cf. De Roo, 2012; Boelens and De Roo, 2016). It means that destinations are continually influenced by and responding to dynamics of other destinations and systems and are in need of the adaptive capacity to do so (Hartman, 2016). Here, the interactions and actions of agents are important for the individual actor's adaptive capacity as well as the overall system's capacity to adapt responsively to dynamics in other systems. This capacity to adapt involves a process of change, renewal and transformation and enables systems to what is conceptualized as the coevolution of one system in response to others (Gerrits, 2008). Below, the key factors of agents, interaction, adaptation, feedback loops, self-organization, emergent structures, feedback and feedforward are discussed that according to theories on complexity enable actors within systems to perform adaptive behavior that enables complex system to coevolve to its dynamic context. This review results in a framework of concepts and mechanisms that we subsequently apply on destination development in Section 3 as a means to identify (policy) avenues that help to improve destination governance.

PAGE 2 |JOURNAL OF TOURISM FUTURES $\mid$ VOL. AHEAD-OF-PRINT NO. AHEAD-OF-PRINT 2021 


\subsection{Adaptation, self-organization and emergent structures}

The capacity to adapt is central to the behavior of complex systems. Adaptation can be conceptualized as the process of changing systems' structures and functions, enabling them, on the one hand, to deal with pressures that stem from their contextual environment and, on the other hand, to move to enhanced forms of organization and performance (Heylighen, 2001; Axelrod and Cohen, 2000). Alternatively stated, adaptation involves "an iterative and gradual, stepwise process" that "might take a series of adjustments over a period of time before systems are fundamentally changed in structure, function, organization and identity" (Hartman, 2018b, p. 157). Clearly, central to the process of adaptation are individual agents and their actions that are geared toward achieving improved performance or better situations, given the circumstances at hand that are shaped by the contextual environment, systems properties and individuals' capacities. By means of actions, agents seek to improve their situation and make (small scale) adjustments to (parts of) a system. In tourism, many agents such as entrepreneurs, firms as well as organizations and public institutions seek adaptation, for instance aiming to achieve competitive advantages, improved performances by (re)developing new tourism products and experiences, stimulating sustainability, enhancing livability, etc.

In the context of individual actors' actions, Heylighen (2008, p. 4) explains that "an action by one agent will in general trigger further actions by one or more other agents, possibly setting in motion an extended chain of activity that propagates from agent to agent across the system". Out of small scale, local interactions macroscopic patterns may arise at a system level that are understood as emergent structures (Epstein and Axtell, 1996; Heylighen, 2001; Allen, 2012). In socio-spatial contexts, such structures can be physical, organization and institutional structures. When the collective actions of agents give rise to or change systems' structure spontaneously without one single agent controlling the entire process, it is referred to as self-organization (Heylighen, 2008; Rauws, 2016).

The structures that are created subsequently influence agents, possibly organizing and coordinating their actions to a certain extent and potentially also constraining them in their individual actions (Heylighen, 2001). Rauws (2016) argues that structures may be formal or informal and may be constructed amongst individual actors themselves (self-governance), designed in formal, government settings (hierarchical governance) and designed in cocreation (shared or cogovernance). Dooley (1996) therefore sees that agents are semi-autonomous as they (1) interact in interdependent ways, (2) produce system-wide structures and (3) such that those structure influence behavior of the agents. This brings Kauffman and Weinberger (1989) to the conclusion that adaptation is "a complex combinatorial optimization process" (p. 211).

\subsection{Feedback mechanisms and out-of-equilibrium state}

In relation to adaptation, Kauffman (1993) observes that "many parts and processes must become coordinated to achieve some measure of overall success, but conflicting 'design constraints' limit the results achieved" (p. 33). Emergent organizational and institutional structures, as an examples, may serve as mechanisms that provide feedback (learning and adapting) and feed forward loops (predicting, planning) and can have a positive effect by amplifying or reinforcing actions and negative effects by dampening or suppressing actions (Heylighen et al., 2007). Such mechanisms help systems to identify, learn from and further stimulate actions that may lead to enhanced forms of organization and performance. Heylighen et al. (2007) point out that agents may initially be driven by individual goals, ignorant of long-term effects of their actions and seek goals via trial and error. Actions may differ from or even conflict with actions of other agents aiming to reach their goals. However, agents can learn by means of actions and their impacts on goals of others, through these interactions get to know other agents and mutual interdependencies and may adjust their actions to reduce friction and increase synergies. Actors might reap less optimal results from an individual's perspective but still be able to progress. Subsequently, communities of mutually adapted agents may arise, 
showing signs of organization and cooperation, and give rise to emergent structures that influence even more agents. Whereas this process could result in relatively stable structures and behaviors, external perturbations and internal responses and related tensions can trigger new rounds of adaptation (Heylighen et al., 2007). De Roo (2012) concludes that the ongoing dynamic-adaptive behavior makes that complex systems are always "out-of-equilibrium" ( $p$. 153). The structures, functions, identities and feedbacks of systems are continuously produced, reproduced, adapted and may over longer periods of time fundamentally change.

The dynamic-adaptive behavior of complex adaptive systems makes systems so to say "balance on the edge of order and chaos," where there is maximum creativity and adaptive capacity (Waldrop, 1992). On the one hand, it involves processes of adaptive actions by individual agents, interactions and the creation of supportive structures that reinforce agents' behavior. On the other hand, agents' behavior may collide and conflict and individuals may need to adjust their actions. This will take time and require functioning (self-)corrective feedback mechanisms. Whereas the dynamic-adaptive behavior of complex adaptive systems allows for coping with the pressures that stem from their contextual environment, the process of adaptation could be a sometimes messy learning process that involves trail and error and the ongoing (re-)adjustments of structures. In the context of the emergence and management of tourism destination development, such perspective seems fitting and therefore relevant to further explore.

\subsection{Analytical leverage of complexity theories}

Theories of complex adaptive systems offer a framework of concepts and mechanisms that, potentially, offers analytical leverage to an enhanced understanding of tourism destination development. In our analytical framework that we use in the next sections to theorize tourism destination development and identify (policy) avenues to improve destination governance, we take on board the following main aspects. First, the differentiation between multiple levels, particularly those of the level of individual, the level of structures, the level of the structure-agent interface and the level of the overall system. Second, the steps in the process of adaptation that take place on and between these different levels (see Figure 1): the influence of a changing contextual environment (no. 0), how semi-autonomous agents adapt and interact to these influences (no. 1), how agents create systems-wide patterns, structures and properties (no. 2.) and how these in turn influence agents (no. 3). Third, time as factor needs to be taken into account as processes do not play out instantaneous but may take a while before feedback mechanisms work, actions are adjusted and structures changed. These aspects contribute to the adaptive behavior of systems and take place in the context of continually changing contextual environment that influence dynamics within these open systems.

\section{Figure 1 Mechanisms in the process of adaptation, based on Lewin (1999) and Dooley (1996), adapted by authors}

0. Changing contextual environment influencing dynamics within 'open systems' (opportunities, pressures, disturbances)

1. Semi-autonomous agents interact in interdependent ways (adaptation, interaction, selforganisation)
2. Produce system-wide patterns, structures and properties (emergent structures)

3. Patterns, structures and properties such that influence behaviour of agents (positive and negative feedback) 


\section{Exploring tourism destination development from a complexity perspective}

The process of tourism destination development, traditionally related by Butler's TALC model (Butler, 1980) to an increasing number of tourist and recently increasingly associated with the (perceived) emergence of overtourism, is a result of a complex confluence of factors that build up and reinforce each other over a (longer) period of time. It involves the choices and actions of a range of local actors, the (re)design of institutional frameworks and decision-making by visitors. The sections below make use of the analytical framework introduced earlier (including Figure 1) to conceptualize the process of tourism destination development. Subsequently, we discuss possible (policy) avenues to improve destination governance in the following sections and also critically reflect on the use of this perspective.

\subsection{The level of individuals (agency)}

The sum of individual choices and actions of entrepreneurs in the tourism industry is a key contributor to destination development. Many individuals are driven by their personal search of finding optimal situations for themselves. Theoretically, individuals pursue an individual (local) optimum by means of a stepwise adaptive process (Kauffman and Levin, 1987). Generally, this is (still) largely economically driven being motivated by generating income, acquiring returns on investment and reaching higher welfare standards. When returns on investments are generated, this may drive entrepreneurs to further investments for instance in order to reach economies of scale and larger market shares. Family business may become chains, startups become scale-ups or TNC's and places may see an influx of similar types of shops (e.g. many cheese, ice cream and Nutella shops in Amsterdam) as a result of growth plans, franchises and copy-cat behavior. Many of which are seeking to target tourists, triggered by their affluence, spending behavior and seemingly ever increasing volumes. Growth models are sought to increase profits, are needed to pay off debts or interest rates, or are desired by investors seeking their annual growth percentages. These processes relate to self-organization: the autonomous decisions and actions of individuals as triggered by their local contexts. Over time, processes of self-organization result in emergent structures (Rauws, 2016), e.g. the individuals that rent out their spare bedrooms, facilitated by AirBnB, are drivers of a local sharing economy movement that triggers the rise of intermediary organizations, draws political attention, results in policy measures and potentially court cases.

One the one hand, these processes generate an inflow of capital, drive urban and regional (re) development projects, create jobs, generate income and enhance welfare. This tends to fit in well with neoliberal ways of thinking in which maximizing individual freedom, stimulating privatization, commercialization and globalization (Mosedale, 2016). On the other hand, these processes are strong factors in driving gentrification, displacement and perceived losses of authenticity and livability as a result of changing local identities, out-flow of original host communities and their activities, increase of real-estate prices, visitors numbers (crowdedness) and excess behavior of visitors (noise, pollution). A process very similar to the tragedy of the commons and challenges related to governing the commons (Hardin, 1968; Dietz et al., 2003). Overall, what is considered optimal for one might not the considered optimal by others. Differences in motives and interest may arise between individuals and groups, possibly resulting in discussions, negotiations or even disputes and clashes when tolerance levels are exceeded (cf. Doxey, 1975; on the irritation index or Postma and Schmücker, 2017; on critical tourism encounters). As a result of the adaptive behavior of individuals and their collective action, places are being (re)developed as tourism destinations and physical structures, functions and identities aligned to those purposes. Other types of structures are put in place as well such as institutional frameworks operating as positive and negative feedback mechanisms as the following subsection explains.

\subsection{The level of (emergent) structures}

The behavior of individual agents can be influenced by structures that are put in place (see Figure 1). Structures that provide positive and negative feedback are amongst others 
institutional frameworks, defined as the ensemble of formal rules (laws, regulations and procedures), policies and informal constraints (norms and codes of conduct) that circumscribe the range of actions of the plurality of actors involved in decision-making and implementation (Affolderbach and Parra, 2012). Institutional frameworks can have dampening effects (negative feedback) and at the same time amplifying effects (positive feedback) on development processes. Dampening effects are caused for instance by means of instruments such as restrictive zoning plans, conditions accompanying permits for development projects and activities and boundaries related to carrying capacity (number of visitors, hotels and beds). Amplifying effects can be caused by (the same) instruments such as zoning plans with much freedom, nonrestrictive or absent permit systems for development projects and activities (e.g. AirBnb), investment schemes, development councils and infrastructure development plans that provide for larger capacities. Both lists of dampening and amplifying effects can be massively extended. The point is institutional frameworks are relevant as they work as both enablers as well as constrainers. How institutional frameworks are designed shapes the space of possibilities at the level of individuals for instance for entrepreneurs in the tourism industry to develop their activities. These frameworks have the capacity to "privilege some actors, some identities, some strategies, some spatial and temporal horizons, some actions over others" (Jessop, 2008, p. 236). Generally, the design of institutional frameworks ("institutional design") sits within the realm of governments and politics. How institutional frameworks are designed depends on the local political compositions and how the influence of regional, national and international choices and decisions tickle-through. Hence, a regime that pursues more neoliberal ideologies might provide a larger space of possibilities as a (laissez-faire) strategy to stimulate entrepreneurial spirit and spur economic development compared to regimes that pursue more green or socialist ideologies and more actively aim to intervene in the behavior of individuals.

\subsection{The level of structure-agency interface}

Whereas the institutional frameworks shape the patterns of individual actions and interactions that produce social phenomena, such as overtourism, those same institutional frameworks are emergent structures out of such interactions. The actions of individuals, particularly their cumulative actions, may trigger local but also up to national governments and politicians to (re) design institutional frameworks. For instance, in many destinations, the emergence and growth of Airbnb fuels discussions and attempts to regulate and manage its growth and impacts. New regulatory frameworks are created and imposed on local actors, e.g. limiting the amount of days that houses and apartments can be rented out on Airbnb, installing a permit system for reasons of taxation or strategic planning, enforcing a "hotel stop" to cap a maximum of accommodation capacity, limiting permits for tourist-only shops and many more examples (cf. Peeters et al., 2018). Institutional frameworks are in fact continually renegotiated and reflexively reorganized. This is widely explored by Jessop $(2005,2008)$, and for instance by Pastras and Bramwel (2013) for tourism policy, in the context of the strategic-relational approach, elaborating on the interactions between structure and agency and the (reflexive) reorganization of institutional structures through the actions of agents (agency).

The level of the structure-agency interface is where processes of governance take place. Clearly, how governance processes take place and play out influences the rise of destination development in the first place, but also the ways in which tourism development is locally manifested and how (or the extent to which) tourism industry development can be addressed. Here, we must note that the design of institutional frameworks influences processes of governance. The term governance implications is used in the context of how institutional frameworks affect the ways in which actors engage in making, setting and implementing approaches, in our case geared toward tourism destination development (Hartman et al., 2016).

Ideally, all relevant actors (stakeholders) are involved in processes of governance. This would allow different actors with different interest to partake in discussions, negotiate about visions, strategies 
and measures, and so to finally coshape institutional frameworks. Institutional frameworks would then be based on inclusive, integral approach to tourism and destination development. Outcomes would be supported and respected. In practice, however, often not all actors involved. Reality is unruly. There is a range of factors such as the lack of time, money, connectivity, organizational structures and capacities, formal planning procedures and political standpoints that impede various actors and groups from being involved in governance processes (Hartman et al., 2020). Moreover, the responsibility to manage tourism destination development is often dispersed over different actors (governments, destination management organizations, nongovernmental organizations (TNC), small and medium-sized enterprises (SMEs), transnational companies (TNCs) and within governments also dispersed over multiple levels, domains or departments (e.g. economic affairs, environment and infrastructure, spatial planning, social affairs, culture and heritage, and nature and ecology). As a result, decisions aiming to manage destinations' development are potentially made without full information or consultation let alone consensus among all stakeholders. Subsequently, such decisions can easily be criticized for being ad hoc, too narrow in scope, too reactive, too responsive, too much focusing on resolving symptoms over a developing and implementing a well-wrought strategy that is based on a well-informed and cocreated vision on tourism and destination development.

In this context, controversially as well as ironically, phenomena such as overtourism or COVID-19 can fuel and accelerate discussions about sustainable tourism destination development. For instance, overtourism has proven to be an urgent and powerful phenomenon capable to push tourism destination development high on policy and research agendas, mobilize resources, change voting behavior of inhabitants, fuel new policy programs, adjust institutional frameworks and influence approaches to governance to become more inclusive. Discussions range from solving acute problems to the more strategic challenge of preventing problems, anticipating tourism growth and sustainable destination management.

\subsection{The level of systems}

The system level is where the outcomes emerge of the interplay between processes of governance (interface level), institutional frameworks (structures) and the self-organized actions of local actors (agency). A possible outcome of this interplay is that places over (a long period of time are developed as tourism destinations, as a result of local assets, entrepreneurial spirit and supportive institutional and policy frameworks and political ambitions and decisions. Places can become recognized as interesting places to visit by tourist and, as a consequence, also developed, organized, branded and marketed as such. In these places elements, agents and their actions are tied very closely to other elements, agents and their actions and show collective, coordinated action.

The forces that contribute to the emergence and development of tourism destinations can be strong and self-reinforcing. Over time, many places become largely or entirely dependent on tourism - from cities, villages, islands to entire regions. As discussed earlier in this article, this pathway brings many opportunities for socioeconomic and spatial development but can also have a range of negative impacts. Here, emergent discussions on topics such as overtourism but also destination stewardship or regenerative tourism, at a system level, relate to an (emerging) overemphasis on tourism development and a desire to achieve more balanced situations. Whether such claims are considered credible, salient and will be addressed is subject to discussion and negotiation in processes of governance. More interesting about these claims concerning increasing visitor pressure is that they, albeit implicitly or explicitly, draw attention to and raise awareness about a more fundamental discussion about future perspectives on the overall development of places frequently visited by tourists. Claims concerning visitor pressure, overtourism, destination stewardship, as well as regenerative tourism revolve around the argument that tourism destinations are not only there to meet the demands and desires of (an often growing number) tourists. Destinations are also places for local people and their practices - actors and activities that do not or not necessarily match with destination development, tourism activities and tourist behavior. 
To address and accommodate the wide ranging interests of inhabitants and other nontourism sectors, it is necessary to create ideas about and visions on future states of places to achieve and states of places to avoid, and understand the role of tourism therein. Doing so massively widens the debate from discussing tourism futures and solving issues such as overtourism to an integral discussion about the futures of places. In other words, the system level is critical. It is at the system level where strategic storytelling needs to take place about future situations to achieve and situation to avoid (Hartman et al., 2019), to create more formal visions, to translate visions into strategic plans and adjust the level of institutional frameworks accordingly for proper execution and enforcement. This requires strategic action and leadership (Boal and Schultz, 2007). Many of these aspects concerning the system level takes place in the realm of decision-making and politics. The political couleur locale can be strongly decisive in whether tourism is treated as a separate domain or sector or whether it is addressed as an integral, crosscutting theme alongside other themes that are high on the agendas. Paradoxically, while a phenomenon such as overtourism can be a result of a strong sectoral approach to tourism, it can also be a trigger to adopt more integral approach as actors are confronted with the complexity and the extent to which tourism is interconnected with other forces that shape place development. Ideally, a reactive problem-solving approach oriented toward managing overtourism is redundant as the result of a proactive approach aiming to develop attractive places to live and work as well as visit (frequently) by tourists. Whereas this type of wording can already be found in the 2002 Cape Town Declaration on Responsible Tourism in Destinations that refers to "making better places for people to live in, and better places to visit", designing adequate systems for destination governance remains a challenge due to the complexities of destination development and management (Hartman, 2018a).

\section{Discussion and conclusions: analytical leverage and possible policy avenues}

Theories of complex adaptive systems (CAS) offer an analytical lens to further conceptualize tourism destination development, drawing attention in particular to the multiple levels involved, the steps related to the process of adaptation and the importance of taking into account the factor of time. It offers a framework for analysis that can be projected on tourism destination development and allows us to consider them as complex, open systems that consist of interdependent agents with capacities to interact, adapt and over time change system structures and hence allow systems to coevolve along with the dynamics of the network society and globalized economy. In this context, destination development is the outcome of an adaptive-evolutionary process, and efforts aimed at managing destinations could benefit from taking this perspective into account. Adaptive because it relates to the choices and actions of individuals, the (re)design of institutional frameworks and processes of governance that took place on and between various levels. Evolutionary because of the adaptive behavior of interacting agents at multiple scales that over time collectively shape a system's (recognizable) physical and organizational structures and identities. We can then frame phenomenon such as overtourism in the context of the adaptive-evolutionary development of tourism destinations in order to better understand such phenomenon, on one hand, but, on the other hand, also identify overarching (or underlying) challenge of enabling tourism destination to evolve toward desired states through the adaptive behavior of agents. Structured by the multilevel understanding of destination development (see Figure 1), we see the following avenues for (strategic) tourism planning and policy.

At the level of individuals, the space is needed for individuals to act as change agents, shown their entrepreneurial spirits and perform adaptive behavior, so to adjust to the changing environment and produce new, better tourism experiences that engage visitors and reinforce the competitive position of that individual or firm. More strategically, such actions are important to enhance a system's overall diversity. Generating diversity is important for finding solutions to issues that arise when circumstance change (Heylighen, 2001). In line, Mitleton-Kelly (2003) observes the following for systems in dynamic environments: "to survive and thrive an entity needs to explore its space of possibilities and to generate variety" (p. 14). Diversity helps to prevent collapses when particular products, businesses or organizations are replaced or disappear for instance due to bankruptcy.

PAGE 8 | JOURNAL OF TOURISM FUTURES $\mid$ VOL. AHEAD-OF-PRINT NO. AHEAD-OF-PRINT 2021 
On the scale of a destination, it becomes possible to cope with changes in the economy, in demand, in competitiveness, etc. Fostering a degree of diversity involves experimentation, room for innovations and provides a range of alternatives that make shifting development paths possible. This requires adequate funding schemes, room in zoning plans, building trust amongst stakeholders, organizing capacity and entrepreneurship. A challenge is that too much diversity or overstimulating diversity, on the one hand, and too little diversity or the other could both be counterproductive and requires governing diversity to find a degree of diversity that enables systems to be both robust as well as flexible at the same time (Hartman, 2016). Hence, there is a need for policy frameworks and institutional structures, which is discussed in more detail below.

A the level of structures, there is a need for actors to actively and cocreatively design the space of possibilities for the actions of individuals: institutional frameworks that offer a carefully designed space of possibilities that allow actors to pursue their individual desires, trigger them to contribute to collective goals and desirable system states. Whereas the authority to formalize and institutionalize such space of possibilities with the help of laws, rules, regulations or zoning plans is often with governments, many stakeholders can be actively involved in design phases that take place prior to decision-making. Organizing settings wherein such cocreation can take place requires a deliberate choice for complexity (see below) and therefore thought-leadership, a carefully designed process and quite some organizing capacity and (financial) resources. This approach differs substantially from expert driven strategic planning models and design master plans.

At the level of the interface, discussion (need to) take place that result in the (re)negotiation, (re) design, (re)production and reflexive reorganization of institutional framework that shape spaces of possibilities for the actions of individuals. For instance, what is considered "desirable" is likely to change over time due to new technological possibilities, advances in healthcare, levels of welfare, emergent discourses, and so on. This means that strategic storytelling and visioning regarding system states to achieve and to avoid, and the subsequent (re)design of the space of possibilities is an ongoing process that involves multiple levels as addressed earlier. Designing multilevel governance systems that allow for these particular processes to take place is an emerging challenge that requires increasing attention.

At the system level, there is a challenge to engage in strategic storytelling and visioning about structures, functions and identities of system to achieve and those to avoid (Hartman et al., 2019). The recent debates on overtourism have shown the important of an integral focus on the (re) development of places - ranging from cities, to villages and to nature area. Shifting the focus from destinations to places concerns adjusting strategic planning, decision-making and policy-making and involves a (deliberate) choice to embrace complexity (Zuidema, 2016) and show strategic leadership (Boal and Schultz, 2007) as it encompasses an increase of the involved number of actors, domains, goals and options (cf. Dewulf et al., 2009). A refocus from destinations to places could have as an effect that tourism is not the main, major aspect but only just one of the elements in shaping or making places or is overtaken by other interests (cf. Lew, 2017). Already development models are more and more geared toward the contribution to (a combination of sustainability (SDGs), quality of life, liveability and/or well-being. Such models go beyond the current models for tourism development that still revolve very much around economics and growth.

Finally, the factor time is crucial in system dynamics. Time is needed for dynamics to take place and to play out. In complex adaptive systems, it takes time to create structures including those that produce overtourism and it will likely also take time to renegotiate and reorganize these structures hence also to solve overtourism-related issues and causes. For instance, it will involve the introduction of new perspectives, stories about futures to avoid and achieve, policies, laws, regulations, new feedback loops, e.g. to involve inhabitants more closely, new business models and organizational networks, etc. Particularly when there is no single actor in complete control over a tourism destination (similar to complex adaptive systems), which is the case for many destinations as responsibilities, tasks and actions are dispersed over many actors and often over difference governance levels. The emergence of a phenomenon such as overtourism is then the result of a "complex combinatorial optimization process" (cf. Kauffman and Weinberger, 1989, p. 211) and makes an easy and structural fix in the 
context of sustainable destination development in a (very) short period of time unlikely. Old system's structures, functions, identities and practices need to be destabilized and broken-down to phase out and new ones need to emerge and stabilize (Loorbach et al., 2017).

Theories of complex adaptive systems can contribute to an adaptive-evolutionary understanding as well as approach to tourism destination development and management. It allows to further develop the understandings of the structural dynamics and structural challenges that needs to be addressed concerning tourism development, and via this way also complement to advances made on emerging and potentially temporary phenomenon such as overtourism. On a critical note, managing tourism destination as complex adaptive systems requires embracing a complexity perspective, which is a matter of choice and comes with many conditions (e.g. ensuring experiments, diversity and self-organization for adaptation, the reflexive reorganization of institutional and governance structure). Furthermore, meeting these conditions requires a substantial amount of resources, organizational capacity, extensive comprehensive and functioning organization structures, institutional structures and thus overall governance system. Currently, many debates take place on the level of individuals, the institutional level and/or the interface level, whereas the system level is often missing or avoided in discussions for various reasons. For instance, it could be unclear who is/are politically responsible for the overall system, it could be that tourism is not on the policy agenda of actors that aim to govern the system, institutional structures could be organized in silos and rigid policy domains that hamper integrative thinking and thematic approaches, it could be a practical move too avoid complexity, it could relate to general lack of capacity and many more. Nevertheless, discussions about desirable systems structures, functions and identities is a key element, being interlinked to the other specified levels, that may complement debate on fixing phenomena such as overtourism with dealing with the structural issue of adaptive capacity building for tourism destinations.

\section{References}

Affolderbach, J. and Parra, C. (2012), "Cross-disciplinary perspectives on governance", in Affolderbach, J., DuBry, T., Gonzalez, O. and Parra, C. (Eds), Reinforcing Governance: Perspectives on Development, Poverty and Global Crises, P.I.E. Peter Lang, Brussels, pp. 11-27.

Allen, P.M. (2012), "Cities: the visible expression of Co-evolving complexity", in Portugali, J., Meyer, H., Stolk, E. and Tan, E. (Eds), Complexity Theories of Cities Have Come of Age: An Overview with Implications to Urban Planning and Design, Springer, Berlin, pp. 67-90.

Amore, A. and Hall, C.M. (2016), "From governance to meta-governance in tourism? Re-incorporating politics, interests and values in the analysis of tourism governance", Tourism Recreation Research, Vol. 41 No. 2, pp. 109-122, doi: 10.1080/02508281.2016.1151162.

Axelrod, R. and Cohen, M. (2000), Harnessing Complexity: Organizational Implications of a Scientific Frontier, Basic Books, New York.

Baggio, R. (2008), "Symptoms of complexity in a tourism system", Tourism Analysis, Vol. 13 No. 1, pp. 1-20.

Baggio, R., Scott, N. and Cooper, C. (2010), "Improving tourism destination governance: a complexity science approach", Tourism Review, Vol. 65 No. 4, pp. 51-60, doi: 10.1108/16605371011093863.

Boal, K.B. and Schultz, P.L. (2007), "Storytelling, time, and evolution: the role of strategic leadership in complex adaptive systems", The Leadership Quarterly, Vol. 18 No. 4, pp. 411-428.

Boelens, L. and De Roo, G. (2016), "Planning of undefined becoming: first encounters of planners beyond the plan", Planning Theory, Vol. 15 No. 1, pp. 42-67.

Brouder, P. and Eriksson, R.H. (2013), "Tourism evolution: on the synergies of tourism studies and evolutionairy economic geography”, Annals of Tourism Research, Vol. 43, pp. 370-389.

Butler, R. (1980), "The concept of a tourist area cycle of evolution: implications for management of resources", Canadian Geographer / Le Géographe canadien, Vol. 24, pp. 5-12.

De Roo, G. (2012), "Spatial planning, complexity and a world 'out of equilibrium' - outline of a non-linear approach to planning", in de Roo, G., Hillier, J. and van Wezemael, J. (Eds), Planning and Complexity: Systems, Assemblages and Simulations, Ashgate, Farnham, pp. 129-166. 
Dewulf, A.R.P.J., Termeer, C.J.A.M., Werkman, R.A., Breemen, G.E. and Poppe, K.J. (2009), "Transition management for sustainability: towards a multiple theory approach", in Poppe, K.J., Termeer, C.J.A.M. and Slingerland, M. (Eds), Transitions towards Sustainable Agriculture and Food Chains in Peri-Urban Areas, Academic Publishers, Wageningen, pp. 25-50.

Dietz, T., Ostrom, E. and Stern, P.C. (2003), "The struggle to govern the commons", Science, Vol. 302 No. 5652, pp. 1907-1912.

Dooley, K. (1996), "A nominal definition of complex adaptive systems", The Chaos Network, Vol. 8 No. 1 , pp. 2-3.

Doxey, G. (1975), "A causation theory of visitor-resident irritants, methodology and research inferences. The impact of tourism", In Proceedings of the Sixth Annual Conference Proceedings of the Travel Research Association, San Diego, CA, USA, 8-11 September 1975.

Farrell, B.H. and Twining-Ward, L. (2003), "Reconceptualizing tourism”, Annals of Tourism Research, Vol. 31 No. 2, pp. 274-295, doi: 10.1016/j.annals.2003.12.002.

Faulkner, B. and Russell, R. (1997), "Chaos and complexity in tourism: in search of a new perspective", Pacific Tourism Review, Vol. 1 No. 2, pp. 93-102.

Gerrits, L. (2008), The Gentle Art of Coevolution: A Complexity Theory Perspective on Decision Making Over Estuaries in Germany, Belgium and the Netherlands, Optima Grafische Communicatie, Rotterdam.

Hardin, G. (1968), "The tragedy of the commons”, Science, Vol. 162 No. 3859, pp. 1243-1248.

Hartman, S. (2016), "Towards adaptive tourism areas? A complexity perspective to examine the conditions for adaptive capacity”, Journal of Sustainable Tourism, Vol. 24 No. 2, pp. 299-314, doi: 10.1080/09669582. 2015.1062017.

Hartman, S. (2018a), "Resilient tourism destinations? Governance implications of bringing theories of resilience and adaptive capacity to tourism practice", in Innerhofer, E., Fontanari, M. and Pechlaner, H. (Eds), Destination Resilience - Challenges and Opportunities for Destination Management and Governance, Routledge, Abingdon, pp. 66-75.

Hartman, S. (2018b), "Towards adaptive tourism areas: using fitness landscapes for managing and futureproofing tourism area development", Journal of Tourism Futures, Vol. 4 No. 2, pp. 152-162, doi: 10.1108/JTF-03-2018-0009.

Hartman, S. (2020), "Adaptive tourism areas in times of change", Annals of Tourism Research, Vol. 87, doi: 10.1016/j.annals.2020.102987.

Hartman, S., Parra, C. and De Roo, G. (2016), "Stimulating spatial quality? Unpacking the approach of the province of Friesland, the Netherlands", European Planning Studies, Vol. 24 No. 2, pp. 297-315, doi: 10.1080/09654313.2015.1080229.

Hartman, S., Parra, C. and De Roo, G. (2019), "Framing strategic storytelling in the context of transition management to stimulate tourism destination development", Tourism Management, Vol. 75, pp. 90-98, doi: 10.1016/j.tourman.2019.04.014.

Hartman, S., Wielenga, B. and Heslinga, J. (2020), "The future of tourism destination management: building productive coalitions of actor networks for complex destination development", Journal of Tourism Futures, Vol. 6 No. 3, doi: 10.1108/JTF-11-2019-0123.

Heylighen, F. (2001), "The science of self-organization and adaptivity”, in Kiel, L.D. (Eds), The Encyclopedia of Life Support Systems, Eolss Publishers, Oxford, pp. 253-280.

Heylighen, F. (2008), “Complexity and self-organization”, in Bates, M.J. and Maack, M.N. (Eds), Encyclopedia of Library and Information Sciences, Taylor \& Francis, New York, NY.

Heylighen, F., Cilliers, P. and Gershenson, C. (2007), "Philosophy and complexity", in Bogg, J. and Geyer, R. (Eds), Complexity, Science and Society, Radcliffe, Oxford, pp. 117-134.

Jessop, B. (2005), "Critical realism and the strategic relational approach”, New Formations, Vol. 58, pp. 40-53.

Jessop, B. (2008), State Power, Polity Press, Cambridge.

Jessop, B. (2011), "Metagovernance", in Bevir, M. (Ed.), The SAGE Handbook of Governance, Sage, London, pp. 106-123.

Kauffman, S.A. (1993), Origins of Order: Self Organization and Selection in Evolution, Oxford University Press, Oxford. 
Kauffman, S.A. and Levin, S. (1987), "Towards a general theory of adaptive walks on rugged landscapes", Journal of Theoretical Biology, Vol. 128 No. 1, pp. 11-45.

Kauffman, S.A. and Weinberger, E.D. (1989), "The NK model of rugged fitness landscapes and its application to maturation of the immune response", Journal of Theoretical Biology, Vol. 141 No. 2, pp. 211-224.

Lew, A.A. (2017), "Tourism planning and place making: place-making or placemaking?", Tourism Geographies, Vol. 19 No. 3, pp. 448-466, doi: 10.1080/14616688.2017.1282007.

Lewin, R. (1999), Complexity: Life at the Edge of Chaos, 2nd ed., The University of Chicago Press, Chicago.

Loorbach, D., Frantzeskaki, N. and Avelino, F. (2017), "Sustainability transitions research: transforming science and practice for societal change", Annual Review of Environment and Resources, Vol. 42, pp. 599-626, doi: 10.1146/annurev-environ-102014-021340.

Ma, M. and Hassink, R. (2013), "An evolutionary perspective on tourism area development", Annals of Tourism Research, Vol. 41, pp. 89-109.

Mitleton-Kelly, E. (2003), "Ten principles of complexity and enabling infrastructures", in Mitleton-Kelly, E. (Ed.), Complex Systems and Evolutionary Perspectives of Organisations: The Application of Complexity Theory to Organizations, Elsevier Science, Oxford, pp. 23-50.

Mosedale, J. (2016), Neoliberalism and the Political Economy of Tourism, Routledge, Abingdon.

Pastras, P. and Bramwell, B. (2013), "A strategic-relational approach to tourism policy", Annals of Tourism Research, Vol. 43, pp. 390-414.

Peeters, P.M., Gössling, S., Klijs, J., Milano, C., Novelli, M., Dijkmans, C.H.S., Eijgelaar, E., Hartman, S., Heslinga, J., Isaac, R., Mitas, O., Moretti, S., Nawijn, J., Papp, B. and Postma, A. (2018), "Research for TRAN Committee - Overtourism: impact and possible policy responses", European Parliament, Directorate General for Internal Policies, Policy Department B: Structural and Cohesion Policies, Transport and Tourism, doi: 10.2861/919195.

Postma, A. and Schmüecker, D. (2017), "Understanding and overcoming negative impacts of tourism in city destinations: conceptual model and strategic framework", Journal of Tourism Futures, Vol. 3 No. 2, pp. 144-156, doi: 10.1108/JTF-04-2017-0022.

Rauws, W. (2016), "Civic initiatives in urban development: self-governance versus self-organisation in planning practice”, Town Planning Review, Vol. 87 No. 3, pp. 339-361, doi: 10.3828/tpr.2016.23.

Schianetz, K. and Kavanagh, L. (2008), "Sustainability indicators for tourism destinations: a complex adaptive systems approach using systemic indicator systems", Journal of Sustainable Tourism, Vol. 16 No. 6, pp. 601-628.

Stevenson, N., Airey, D. and Miller, G. (2009), "Complexity theory and tourism policy research", International Journal of Tourism Policy, University Press, Vol. 2 No. 3, pp. 206-220.

Swyngedouw, E. (2005), "Governance innovation and the citizen: the Janus face of governance beyond-thestate”, Urban Studies, Vol. 42 No. 11, pp. 1991-2006.

Waldrop, M. (1992), Complexity: The Emerging Science at the Edge of Order and Chaos, Penguin Books, London.

Yang, Z., Yin, M., Xu, J. and Lin, W. (2019), "Spatial evolution model of tourist destinations based on complex adaptive system theory: a case study of Southern Anhui, China", Journal of Geographical Sciences, Vol. 29, pp. 1411-1434, doi: 10.1007/s11442-019-1669-z.

Zuidema, C. (2016), Decentralization in Environmental Governance, a Post-contingency Approach, Routledge, London, doi: 10.4324/9781315593357.

\section{Corresponding author}

Stefan Hartman can be contacted at: stefan.hartman@nhlstenden.com

For instructions on how to order reprints of this article, please visit our website: www.emeraldgrouppublishing.com/licensing/reprints.htm Or contact us for further details: permissions@emeraldinsight.com 